Quim. Nova, Vol. 35, No. 4, 844-850, 2012

\title{
DIFERENTES OLHARES ACERCA DOS CONHECIMENTOS NECESSÁRIOS NA FORMAÇÃO INICIAL DO PROFESSOR DE QUÍMICA
}

\author{
Sidilene Aquino de Farias* \\ Departamento de Química, Universidade Federal do Amazonas, Setor Norte do Campus Universitário Senador Arthur Virgílio \\ Filho, Av. Gal. Rodrigo Octávio Jordão Ramos, 3.000, 69077-000 Manaus - AM, Brasil \\ Luiz Henrique Ferreira \\ Departamento de Química, Universidade Federal de São Carlos, CP 676, 13560-970 São Carlos - SP, Brasil
}

Recebido em 9/5/11; aceito em 27/9/11; publicado na web em 6/12/11

\begin{abstract}
DIFFERENT PERSPECTIVES ON KNOWLEDGE REQUIRED IN INITIAL TEACHER TRAINING OF CHEMISTRY. This study investigated different understandings about the educational needs of a professor of Chemistry, related to "know" and "know-how". It was verified the convergence and divergence of perceptions of high school students from that point to literature and education legislation. The research was conducted in five states in northern Brazil. The results show the little dialogue between training institutions and secondary schools, since the different understandings about the training needs go in opposite directions.
\end{abstract}

Keywords: pedagogical knowledge; initial formation; formative needs.

\section{INTRODUÇÃO}

Desde a homologação das Diretrizes Curriculares Nacionais (DCNs) para a Formação de Professores da Educação Básica e para os Cursos de Química, o repensar sobre a formação inicial do professor de Química tem sido frequente nos cursos de Licenciatura em Química (LQ). Em alguns cursos foi constatado que esse fato apenas se configura como necessidade de adequação às normas oficiais, sem haver, de fato, preocupação dos agentes formadores em buscar caminhos pautados em orientações teórico-metodológicas para subsidiar as mudanças a serem realizadas nos cursos, que visem a melhoria da formação do professor de Química. ${ }^{1-5}$

Por outro lado, também é possível encontrar, na literatura, narrativas de experiências vivenciadas em alguns cursos de LQ, mesmo antes da implantação das DCNs. Nesse sentido, tais relatos têm se configurado como necessidade de reflexão na busca constante dos melhores caminhos para construção de um currículo comprometido com a formação de cidadãos que promovam transformações na sociedade..$^{6-9}$

Ambas as perspectivas apresentam visões sobre os cursos de formação inicial de professores de Química com base no entendimento das Instituições de Ensino Superior (IES), sejam estabelecidas nos documentos oficiais das instituições - Projetos Político-Pedagógicos (PPP) e Matriz Curricular (MC) - e/ou nas concepções dos sujeitos envolvidos na formação - coordenadores de curso, docentes e licenciandos.

Essa preocupação com a melhoria da qualidade do curso de LQ também tem ganhado espaço nos debates promovidos por entidades civis que visam congregar os profissionais da Química - Conselhos Regionais e Federal de Química (CRQs e CFQ) e Sociedade Brasileira de Química (SBQ). Nesse sentido, a SBQ e o CRQ da IV região têm promovido, desde 2005, encontros de coordenadores de cursos de Graduação em Química - denominados, a partir de 2007, de Fórum Nacional de Coordenadores de Cursos de Graduação em Química. Em relação aos cursos de LQ, os temas debatidos nesses encontros têm sido: PPP do curso; atualização curricular - Prática como Componente Curricular; Estágio Curricular; carga horária dos

\footnotetext{
*e-mail: lenefarias@hotmail.com
}

cursos noturnos; valorização da docência; pesquisa na área de Ensino de Química; entre outros. ${ }^{10}$

\section{ALGUMAS VISÕES ACERCA DA FORMAÇÃO DO PROFESSOR DE QUÍMICA NAS IES}

Estudos que buscam compreender como ocorreu o processo de reformulação/criação dos cursos de LQ de IES públicas diante das novas exigências legais, utilizando como objetos de estudos o PPP, a MC e as concepções dos sujeitos envolvidos na formação inicial do professor de Química - coordenadores de curso, docente formador e licenciandos - têm apontado que o principal elemento norteador das reformulações dos referidos cursos foram as exigências legais. ${ }^{1-3}$ Esse fato foi observado em cursos de LQ de IES públicas em diferentes regiões do país - Nordeste e Sudeste - uma vez que na maioria dos cursos a principal finalidade era adequar a proposta pedagógica destes às DCNs.

Kasseboehmer, ${ }^{1,2}$ ao desenvolver uma pesquisa com nove cursos de LQ e IES públicas paulistas, enfatizou que, para a maioria dos cursos, o processo de reformulação/criação ocorreu sem haver uma compreensão dos modelos de formação de professores presentes na literatura educacional. Além disso, nas concepções tanto de docentes como de discentes acerca do papel do professor na sociedade, a docência se configura como uma atividade de baixo valor, para a qual uma

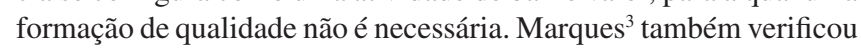
resultados similares numa pesquisa realizada com 16 cursos de LQ da região Nordeste do país. A pesquisadora constatou que nos cursos prevalece o modelo de formação baseado na "Racionalidade Técnica"; assim sendo, os conhecimentos mais valorizados na formação do futuro professor de Química estão relacionados ao aspecto técnicocientífico. Com efeito, na análise dos componentes curriculares "Prática como Componente Curricular" (PCC), observou-se que alguns cursos não contemplaram as $400 \mathrm{~h}$ de atividades da componente PCC e que essa carga horária foi suprimida em detrimento dos conteúdos químicos. ${ }^{1,2}$ Tal constatação também se mostrou similar em um estudo realizado em cursos de LQ na região Norte, especificamente no Estado de Rondônia, uma vez que Francisco Júnior et. al. encontraram situações similares aos cursos da região Sudeste. ${ }^{4}$

Outro estudo acerca da formação do professor de Química, que aponta as concepções dos cursos de LQ das IES goianas, tanto 
públicos como privados, assinala que o perfil do profissional para a maioria dos cursos pesquisados, por meio dos PPPs, não possui clareza sobre o papel do professor de Química e, assim, atribuíram-lhe competências relacionadas ao setor industrial. ${ }^{5}$

Alguns estudos, todavia, apontam a preocupação de grupos de pesquisa da área de Ensino de Química, dentro do próprio curso de LQ, com a melhoria da qualidade da formação docente. Nesse sentido, a proposta de implantação de um currículo de curso noturno de Licenciatura em Química na Universidade de Brasília (UnB) ocorreu bem antes da implantação das DCNs, em 1995. ${ }^{6}$ Naquele momento, o princípio básico e orientador da proposta foi a identidade do curso e para isso foram levadas em consideração a natureza da formação de professores e as características específicas relacionadas ao período de funcionamento. Assim, a construção da proposta pedagógica visava delinear um currículo apoiado nas concepções apresentadas pelas pesquisas educacionais do período. A proposta também buscava compreender a natureza específica de um curso de formação de professores e destacava que a formação profissional, além de dar o domínio da técnica e do conteúdo, necessitava dar competência inerente ao processo educacional que envolve, entre outros aspectos, conhecimentos no campo da psicologia, pedagogia, sociologia e filosofia. Cabe ressaltar que a referida proposta também buscava superar dois fatos bastante relatados nas pesquisas relacionadas à formação inicial de professores: a superação da dicotomia teoria e prática e a configuração adquirida de apêndice dos cursos de bacharelado.

Em propostas pedagógicas mais recentes, o curso de LQ da UnB assumiu uma configuração curricular pautada em quatro princípios: 1) a formação profissional docente assume um espaço curricular específico e tem a finalidade de articular saber educacional e ensino de Química; 2) Didática de Ensino de Química (DEQ) caracteriza-se por meio de disciplinas vinculadas à área de pesquisa em Ensino de Química; 3) prática docente está presente em disciplinas da DEQ, nas disciplinas de estágio e na orientação teórico-metodológica do Trabalho de Conclusão de Curso; 4) estratégias de permanente reconstrução curricular. ${ }^{7,8}$ Nessa proposta, as disciplinas relacionadas ao segundo e terceiro princípios são também um espaço para abordar questões problemáticas vivenciadas pelos professores de Química no cotidiano escolar por meio da pesquisa. A esse respeito, Gauche et al. ${ }^{7}$ assinalam que essa proximidade com a realidade escolar proporciona ao licenciando momentos de problematização e fundamentação das ações e estratégias de intervenção pedagógica e, assim, contribui para uma melhor formação.

Nesse mesmo entendimento, Garcia e Kruger ${ }^{9}$ destacam que o processo de implantação das DCNs para a formação do professor de Química ocorreu na Universidade Federal de Pelotas (UFPel) com intensa participação dos professores da instituição na reformulação do PPP. De acordo com os autores, a formação de professores de Química na instituição está pautada na tematização dos conhecimentos escolares, construção de saberes baseada em experiências, valorização da iniciação científica e a inserção de professores em formação nas práticas docentes desde o início do curso, entre outros. Desse modo, visa aproximar o conhecimento escolar do conhecimento acadêmico, buscando articular a sistematização teórica ao saber fazer por meio da reflexão sobre a prática. Para tanto, propõem que para atingir o perfil profissional almejado, o licenciando deve adquirir conhecimentos a partir da experiência, articulados com uma reflexão sistemática e uma interpretação dessa experiência docente e dos problemas advindos da prática (p. 220). ${ }^{9}$

Embora possam ser encontrados, na literatura, estudos que demonstram a existência de cursos de LQ que visam estruturar suas propostas pedagógicas para além das prescritas nas determinações legais, tais concepções se configuram como casos pontuais nas instituições formadoras, uma vez que estas assumem uma vertente de preparo do futuro professor de Química para atuar de maneira reflexiva, articulando os conhecimentos químico-pedagógicos. De modo geral, as concepções nos cursos de formação de professores de Química centram a formação nos conhecimentos técnico-científicos.

\section{DETERMINAÇÕES LEGAIS E SABERES DOCENTES}

O processo de reformulação/construção de PPPs deve seguir as orientações e determinações legais, tais como a Resolução CNE/CES n. ${ }^{\circ}$ 8/2002 $2^{11}$ - Diretrizes Curriculares para o Curso de Licenciatura em Química, integrantes no Parecer CNE/CES n. ${ }^{\circ} 1.303 / 2001^{12}$ - que descreve o perfil do profissional desejado. Faz-se necessário, entretanto, ir além dessas determinações, buscando a compreensão das normas por intermédio da literatura educacional e do desenvolvimento de pesquisa na área de Educação Química.

As DCNs, para os Cursos de Química, ${ }^{12}$ destacam como principais características do perfil profissional para o professor de Química a formação geral, com uma base aprofundada e abrangente em relação aos conhecimentos químicos, bem como formação pedagógica adequada do conhecimento e de experiências de Química e áreas afins, na atuação profissional como educador na educação básica. Além dessas características, tanto nas DCNs para a Formação de Professores ${ }^{13}$ como para os Cursos de Química, ${ }^{12}$ as orientações assinalam a formação de um professor reflexivo e/ou um professor investigador de sua prática educativa. Essa perspectiva de formação também se mostra necessária diante das demandas suscitadas nas orientações oficiais para a Educação Básica, que por sua vez salientam "que [o que] se deseja, afinal, são professores reflexivos e críticos, [...] com um conhecimento satisfatório das questões relacionadas ao ensino-aprendizagem [...] para desenvolver o trabalho interdisciplinar" ( $p$. 144). ${ }^{14}$ Isso implica na necessidade de repensar a formação inicial do professor, no sentido de refletir sobre quais saberes profissionais são necessários para tornar o professor crítico, reflexivo, consciente de seus limites e possibilidades, e inquiridor de sua prática social. Tais saberes estão vinculados diretamente à função do professor na escola e na sala de aula.

Assim, a base do saber para o ensino é constituída por um conjunto de conhecimentos, habilidades e disposições que são necessários para que o professor possa propiciar processos de ensinar e de aprender em diferentes áreas de conhecimento, níveis, contextos e modalidades de ensino. De modo geral, em relação à tipologia dos saberes docentes, Shulman ${ }^{15,16}$ desenvolveu pesquisas com professores iniciantes e experientes, buscando a compreensão de como é o processo pelo qual a pessoa se torna professor. O autor propôs sete dimensões do saber docente, necessárias à prática educativa dos professores: conhecimento do conteúdo a ser ensinado; conhecimento pedagógico geral, que inclui o domínio dos princípios pedagógicos comuns às várias disciplinas e que se manifestam na gerência e organização da sala de aula; conhecimento do currículo; conhecimento pedagógico do conteúdo, uma combinação entre o conteúdo que se vai ensinar e o conhecimento pedagógico; conhecimento do aluno e das suas características, partindo de suas características gerais, o seu nível de desenvolvimento e aprendizagem, e a sua envolvente sociocultural; conhecimento do contexto educacional e, conhecimento dos fins educativos.

Nessa mesma perspectiva, Cunha ${ }^{17}$ desenvolveu uma pesquisa com o objetivo de identificar as influências mais significativas na construção da identidade docente de professores, baseando-se no desempenho do professor e aprofundando o estudo acerca de sua história de vida. Para tanto, a autora considerou que o saber do professor consiste em duas grandes dimensões - domínio do conteúdo de ensino e domínio das ciências da educação. Para determinar quem seriam os professores que participariam da pesquisa foi feito um levantamento junto aos estudantes buscando "[...] estudar os BONS PROFESSO- 
RES, discutir a própria ideia de BOM PROFESSOR presente hoje nos alunos e localizar no tempo e no espaço esta valoração, em consonância com o contexto social" (p. 47). ${ }^{17}$

As justificativas apresentadas pelos estudantes na atribuição de "bom professor" eram, em sua maioria, relacionadas à interação professor/aluno. Na percepção dos estudantes, características como conhecimento da matéria a ser ensinada ou habilidades para organizar suas aulas se entrelaçam com as maneiras de manter relações positivas. Cumpre, no entanto, destacar que "quando os alunos verbalizam o porquê da escolha do professor, enfatizam os aspectos afetivos" (p. 69). ${ }^{17}$

Além disso, os resultados da pesquisa de Cunha apontam que as atitudes e valores dos professores, que estabelecem relações afetivas com os alunos, se repetem e se intricam na maneira como eles tratam o conteúdo e nas habilidades de ensino que desenvolvem. Dessa forma, a relação professor/aluno passa pelo trato do conteúdo de ensino e, com isso, é possível depreender que a forma como o professor se relaciona com sua área de conhecimento é fundamental, pois essa influencia a relação professor/aluno. Outro aspecto observado por Cunha ${ }^{17}$ é a metodologia do professor. A autora ressalta que parece uma consequência natural, um professor que tem uma boa relação com os alunos se preocupar com os métodos de aprendizagem e procurar formas dialógicas de interação.

No âmbito da formação de professores de Ciências, estudos apontam as necessidades formativas para que o professor possa superar as concepções simplistas de ensino - visão tradicional e técnica do ensino - uma vez que a concepção de formação do professor, tão arraigada e presente nas últimas décadas nos cursos de formação inicial, tem se mostrado ultrapassada. ${ }^{18}$ Tais necessidades levantadas são derivadas de estudos no campo da Didática das Ciências, os quais buscaram o entendimento de que o professor deve "saber" e deve "saber fazer". As contribuições dessas pesquisas resultaram em categorias que se mostram próximas às categorias elaboradas por Shulman, como, por exemplo, conhecer a matéria a ser ensinada; ou detalham as categorias de análise do referido autor - adquirir conhecimentos teóricos sobre a aprendizagem das ciências; saber preparar atividades capazes de gerar uma aprendizagem efetiva; saber dirigir o trabalho dos alunos; entre outras. ${ }^{18}$

Vale destacar, de acordo com Carvalho e Gil-Pérez (p. 21), ${ }^{18}$ que muitos dos trabalhos investigativos encontrados na literatura apontam "[...] para a gravidade de uma carência de conhecimentos da matéria, o que transforma o professor em um transmissor mecânico dos conteúdos do livro-texto". Assim, para conhecer a matéria a ser ensinada, é preciso ir além de conhecer os conteúdos habitualmente ensinados nos cursos superiores.

Além dos conhecimentos supracitados, alguns estudos assinalam que na formação inicial os futuros professores necessitam apreender determinadas posturas, como compromisso ético e moral com a sua profissão. ${ }^{19,20}$ Nesse sentido, os professores devem compreender que a educação é uma forma de intervenção no mundo, e que ensinar é um ato político. ${ }^{20}$

Diante dos diferentes olhares acerca da formação do professor de Química, neste trabalho, buscaram-se conhecer as percepções que os estudantes do Ensino Médio (EM) têm acerca dos conhecimentos químicos e quais os saberes profissionais, diante de suas vivências no cotidiano escolar, que julgam necessários para a formação inicial de professores e que deveriam ser levados em consideração pelas instituições formadoras.

\section{DESENVOLVIMENTO DA PESQUISA}

Os dados apresentados neste trabalho estão relacionados à pesquisa desenvolvida acerca da formação inicial de professores de
Química na região Norte do país. Para tanto, utilizou-se a abordagem qualitativa, adotando-se como fontes de coleta de dados a entrevista semiestruturada e o questionário. De acordo com Fraser e Gondim, ${ }^{21}$ a fala dos atores sociais permite atingir um nível de compreensão da realidade que se torna acessível por meio de discursos, sendo apropriada para investigações cujo objetivo é conhecer como as pessoas percebem o mundo. A coleta de dados foi realizada in loco, participando da pesquisa 26 escolas públicas das redes estaduais de ensino localizadas em 8 cidades de 5 dos 7 Estados da Região Norte: Acre, Amazonas, Pará, Rondônia e Roraima. Os outros dois Estados foram excluídos da pesquisa por não existir curso de LQ nas IES públicas locais.

Participaram da pesquisa estudantes da $3^{\text {a }}$ série do EM - 81 entrevistados e 5.067 respondentes do questionário. Tal escolha pareceu uma proposta bem acertada, uma vez que as pessoas tomam conhecimento do exercício de uma profissão pela vivência de situações e interações com algum profissional, como é o caso da profissão docente, mesmo que a imagem que as pessoas fazem de professor esteja distante do que se espera desse profissional. ${ }^{22}$ Dessa forma, entende-se que a percepção e as representações do estudante acerca da atuação e dos saberes do professor são importantes, pois podem ampliar a nossa compreensão sobre a dinâmica das interações a serem vivenciadas pelos futuros professores em seus ambientes de trabalho.

Na construção e análise dos dados, optou-se pela análise de conteúdo proposta por Bardin, ${ }^{23}$ visto que essa metodologia de análise se constitui em um conjunto de orientações que, por meio de descrições objetivas e sistemáticas do conteúdo das mensagens indicadoras, permitam a inferência de conhecimentos relativos às condições de produção/recepção das mensagens. Em relação às questões fechadas presentes no questionário, as respostas foram contabilizadas, sendo organizadas e expressas graficamente para posterior análise.

\section{RESULTADOS E DISCUSSÃO}

Dos 5.067 estudantes que responderam o questionário, 74,07\% estudam no período diurno e $25,93 \%$ no noturno. Esse baixo número de participantes na pesquisa proveniente do ensino noturno era um resultado esperado, uma vez que dados do Censo da Educação Bási$\mathrm{ca}^{24}$ em relação à matrícula mostram que, em geral, a concentração de estudantes no período diurno é maior.

\section{Percepção acerca dos conhecimentos químicos e características profissionais do professor}

De modo geral, pode-se afirmar que os estudantes do EM consideram que os conhecimentos químicos são, no mínimo, interessantes. Pois quando foram questionados sobre "o que se aprende em Química", a distribuição das respostas dos 5.067 estudantes concentrou-se nos itens "interessante" e "muito interessante". Apenas 19 estudantes deixaram de responder a questão e a soma dos percentuais dos itens mais frequentes corresponde a 90,62\% (interessante/muito interessante), contra $9,00 \%$ da alternativa "pouco interessante".

Pode-se perceber, nos relatos dos entrevistados, os motivos que eles atribuem quando consideram que os conhecimentos químicos são interessantes. Dessa maneira, aproximadamente $82,7 \%$ dos 81 entrevistados afirmaram gostar dos conteúdos químicos e/ou os considerarem interessantes. Só dois entrevistados $(2,4 \%)$ posicionaram-se de forma contrária a tal afirmação e os demais não afirmaram seus posicionamentos, apenas mencionaram alguns fatores condicionantes dos seus interesses pelos conhecimentos da referida ciência. Os estudantes destacaram os seguintes fatores como condicionantes dos seus interesses pelo conhecimento químico: atividades desenvolvidas nas aulas; compromisso do professor com o ensino; assuntos rela- 
cionados ao cotidiano; compreensão que o conhecimento químico pode proporcionar acerca do meio que nos cerca. No caso dos estudantes que afirmaram não gostar de Química, eles atribuíram seus posicionamentos à falta de algum dos fatores condicionantes supramencionados. O trecho abaixo ilustra tal fato:

Não [gosto]. Não consigo aplicar Química pro meu dia a dia, talvez seja a forma que eu estudo. [...] Eu não tenho essa dificuldade [em aprender Química], eu não vejo aplicação. Eu não vejo utilidade na minha vida, então eu acho péssimo eu ter que estudar, meio que desmotivante (Escola 18, Aluno 1).

Em relação ao gostar das aulas de Química, as respostas mais frequentes foram: "gosto", "depende", "mais ou menos" e "não gosto". Cumpre destacar que, aproximadamente, $5 \%$ do total de entrevistados expressaram não gostar das aulas de Química. Na Tabela 1 podem ser observados os principais aspectos destacados pelos estudantes. A maioria dos estudantes expressou gostar das aulas de Química e alguns alunos afirmaram gostar da disciplina. Nos depoimentos, os estudantes descrevem aspectos das aulas, da relação professor/aluno, da relação professor/atividade, compromisso ético do professor com a sua profissão, entre outros.

Tabela 1. Aspectos relacionados ao interesse do estudante do Ensino Médio pelas aulas de Química

\begin{tabular}{ll}
\hline Percepção do estudante & Principais aspectos relacionados \\
\hline & Atividades diferentes, em que os alunos possam \\
& ser mais ativos; \\
& boa explicação; \\
& boa interação com o aluno; \\
& ter domínio do conteúdo; \\
& mostra relação com o cotidiano; \\
Gosto & realiza aulas experimentais; \\
& compromisso ético do professor; \\
& relaciona a Química com assuntos atuais. \\
\hline
\end{tabular}

Atividades propostas:

percepção do professor acerca das dificuldades de

Depende/Mais ou menos aprendizagem dos alunos;

condução das atividades;

conteúdos que despertem o interesse do aluno.

Falta de compromisso do professor;

falta de boa relação com o aluno;

Não gosto

não percebe as relações que a Química possa ter com a vida;

dificuldade de compreensão.

Além disso, demonstram compreender que a profissão de professor lida com alguns fatores que atrapalham tanto no desenvolvimento da aula como na aprendizagem - de modo geral, dificuldade de aprendizagem dos alunos, falta de melhores condições da escola, indisciplina - e que esses fatores podem ser estressantes e podem comprometer o humor do professor.
Diante do exposto, foi possível constatar que os aspectos mencionados pelos estudantes estão intimamente relacionados com as categorias dos tipos de conhecimentos necessários para que o professor possa promover a aprendizagem. ${ }^{15-18} \mathrm{~A}$ partir dos relatos nas entrevistas, é possível depreender que os fatores condicionantes dos interesses pelo conhecimento químico apontados pelos estudantes guardam proximidade com a prática docente do professor, uma vez que na ação docente o professor expressa suas concepções e preocupações acerca da aprendizagem dos seus alunos. Desse jeito, a forma e o conteúdo das suas atividades de ensino, bem como a relação professor/aluno expressam características profissionais do professor. ${ }^{17}$

Outro aspecto importante e destacado pelos estudantes é o compromisso ético e moral que o professor deve ter com relação a sua profissão. Nesse sentido, cabe destacar a não neutralidade do ato pedagógico, visto que a forma de ser e agir do professor revela o seu compromisso com a sua profissão. ${ }^{17,19,20}$

Em relação às características profissionais do professor, pediu-se aos estudantes que citassem três características de um mau professor. Cumpre destacar que, na aplicação do questionário, foi explicado que a questão não estaria relacionada a nenhum professor ou disciplina em particular, mas que, pela vivência deles, fossem citadas três características que um professor não deveria apresentar. Assim, foi obtido um total de 14.037 respostas ( $92 \%$ do esperado). O olhar dado ao conteúdo dos relatos busca extrair das respostas características relacionadas a atitudes e comportamentos que um profissional da área deveria evitar e, ao mesmo tempo, quais saberes seriam necessários para atuar no magistério.

Nessa perspectiva, os defeitos relatados pelos alunos encontramse nos seguintes âmbitos: relação professor/conteúdo a ser ensinado; relação professor/aluno; relação professor/atividade de ensino; relação professor/profissão. Respostas não relacionadas à pergunta foram desconsideradas. Baseando-se nesse entendimento, o conteúdo das 14.037 respostas foi agrupado em quatro categorias: conhecimento da matéria a ser ensinada; conhecimento pedagógico; compromisso ético e moral e, outros. Na Tabela 2, pode ser observada a relação entre as categorias e os relatos dos estudantes que as geraram. Embora as respostas não apresentem todo o conjunto de entendimentos encontrado na literatura, uma vez que os relatos são simples, percebe-se que as inferências encontradas refletem os aspectos abordados.

No âmbito da relação professor/conteúdo, agruparam-se 550 $(3,92 \%)$ relatos do que foi expresso pelos estudantes, na categoria conhecimento da matéria a ser ensinada, percentual bem pequeno se comparado com as demais categorias. Entende-se que é de suma importância que o professor tenha um bom conhecimento da matéria a ser ensinada, uma vez que "Ninguém promove a aprendizagem de conteúdos que não domina nem a constituição de significados que não possui $[\ldots]$ ". ${ }^{13}$

As respostas dos estudantes concentram-se na categoria conhecimento pedagógico $(78,15 \%)$, correspondendo a 10.969 inferências. As respostas agrupadas foram aquelas que faziam alguma inferência às relações professor/atividade de ensino e professor/aluno, que

Tabela 2. Categorias encontradas na determinação das características de um mau professor

\begin{tabular}{lll}
\hline Categorias & Subcategorias & Relatos dos estudantes \\
\hline Conhecimento da matéria a ser ensinada & Não domina o assunto; está totalmente por fora da matéria. \\
\hline $\begin{array}{l}\text { Saber relacionar-se com os } \\
\text { alunos }\end{array}$ & Não dialoga; não se interessar pelo aprendizado do aluno. \\
\cline { 2 - 3 } Conhecimento pedagógico & $\begin{array}{l}\text { Saber preparar e conduzir as } \\
\text { atividades de ensino }\end{array}$ & $\begin{array}{l}\text { Não relacionar a Química com o nosso cotidiano; ausência de estratégia para melhorar o } \\
\text { entendimento; só passa exercício do livro. }\end{array}$ \\
\hline Compromisso ético e moral & Falta de qualificação; sem ética; atrasar; não há interesse de aprender mais. \\
\hline Outros & Feio, pobre, alegre. \\
\hline
\end{tabular}


correspondem às duas subcategorias: saber preparar e conduzir as atividades de ensino e saber relacionar-se com os alunos (Tabela 2). Nessas subcategorias, considera-se imprescindível que o professor adquira conhecimentos relacionados à Psicologia da Educação, pois é necessário considerar a influência dos aspectos afetivos, motivacionais e entender como ocorre a aprendizagem, entre outros, necessários à relação e negociação com o educando, visando à aprendizagem significativa. ${ }^{18}$ A subcategoria que mais contribuiu para o grande percentual foi saber relacionar-se com os alunos, que apresentou 7.518 respostas $(53,56 \%)$. Com relação à subcategoria saber preparar e conduzir as atividades de ensino, esta apresentou o total de 3.451 respostas $(24,59 \%$.).

Assim como na pesquisa desenvolvida por Cunha, ${ }^{17}$ as respostas apresentadas pelos estudantes, em sua maioria, estão relacionadas à interação professor/aluno. Na percepção dos estudantes, características como conhecimento da matéria a ser ensinada ou habilidades para organizar suas aulas são importantes, porém, em razão do alto percentual de respostas, deve-se considerar que os estudantes julgam imprescindíveis relações positivas na sala de aula, para que ocorra aprendizagem.

Numa terceira categoria, agrupamos 2.148 respostas $(15,30 \%)$ no âmbito da relação professor/profissão. Essa é a segunda categoria em número de relatos, embora se comparada com as subcategorias "saber relacionar-se com os alunos" e "saber preparar e conduzir as atividades de ensino" apresente um baixo percentual, ainda assim demonstra a percepção dos alunos em relação ao compromisso do professor com a sua profissão. Nesse sentido, ser profissional da educação implica participar na emancipação das pessoas, uma vez que o objetivo da educação é auxiliar para que se tornem menos dependentes dos poderes econômico e político. Faz-se, portanto, necessário que a formação inicial propicie, além do conhecimento pedagógico específico relacionado à disciplina e da própria disciplina a ser ensinada, “[...] um conhecimento em construção e não imutável, que analisa a educação como um compromisso político prenhe de valores éticos e morais" (p. 18). ${ }^{20}$

Configuraram-se também nos relatos dos estudantes respostas que não caracterizam necessidades que podem ser trabalhadas durante a formação inicial do professor. Assim, foram agrupadas 369 respostas que se mostraram semelhantes na categoria denominada "Outros", com o menor percentual $(2,63 \%)$ de respostas quando comparada com as demais, porém sem comprometer a validade da pesquisa.

Além dos resultados do questionário aplicado, também foram analisadas as 81 entrevistas dos estudantes. Dessa forma, pediu-se para o estudante citar três qualidades de um bom professor e três defeitos de um mau professor. Conforme já mencionado, entende-se que a entrevista permite ao respondente expressar sua opinião com um nível mais profundo da realidade e com mais liberdade. ${ }^{21} \mathrm{De}$ modo geral, as respostas dos estudantes, tanto nas qualidades como nos defeitos, apresentaram as mesmas perspectivas constatadas no questionário, conforme pode ser verificado no trecho abaixo:

\footnotetext{
[...] tem que saber falar, né? Porque uma pessoa que tem conhecimento e uma pessoa que consegue passar o seu conhecimento é algo bem diferente. Ele também tem que ser bem interessado, porque não adianta só o aluno ser interessado, o professor, ele tem que se interessar em dar aula, porque se ele for lá, jogar o conteúdo e fazer a explicação, e não se preocupar realmente se os alunos estão aprendendo ou não, não vai adiantar. E, por último, ele tem que ter um bom posicionamento, um bom caráter, ele tem que ter uma postura boa, pra poder passar confiança pros alunos, pra que esses alunos sintam que podem aprender com ele. Que ele não vai tá sendo enrolado (Escola 14, Aluno 1).
}

Por fim, tornou-se evidente que as características profissionais mais importantes para os estudantes do EM estão relacionadas à formação pedagógica ou ao domínio das ciências da educação. ${ }^{17}$ Cumpre destacar, no entanto, que esse não é o entendimento de muitas das instituições formadoras, como apontam diversos estudos. ${ }^{1-5}$

\section{Necessidades formativas para o professor de Química: percepções dos estudantes do Ensino Médio}

As questões abordadas no item anterior, além de apontarem as características profissionais, começam a delinear quais saberes os estudantes entendem como necessários para formar um professor de Química. Assim, com a finalidade de consolidar essa questão, fez-se a seguinte pergunta aos estudantes: Em sua opinião, o que a universidade deve ensinar para quem deseja ser professor de Química? Para responder tal questão, disponibilizaram-se nove alternativas: teorias químicas; ser divertido; entender as dificuldades do aluno; fazer experimentos; ser exigente; como dar aulas diferentes; pesquisar em Química; ser amigo e mostrar aplicações da Química. Os estudantes foram solicitados a escolher duas alternativas, na ordem de importância. Alguns estudantes não entenderam o que estava sendo solicitado e não responderam corretamente, outros deixaram a questão em branco (nesse caso, apenas 1,1\% para cada uma das ordens de importância).

Para o primeiro mais importante (PI) foram obtidas 5.011 respostas, distribuídas nas nove alternativas. Na Figura 1, pode ser observado que os estudantes consideram como PI, os conhecimentos que permitam entender as dificuldades dos alunos. Essa alternativa corresponde a $1.732(34,18 \%)$ das respostas, seguida de teorias químicas, com 754 $(14,88 \%)$, enquanto que a alternativa que apresentou menor percentual foi pesquisar em Química, com 69 (1,36\%) respostas.

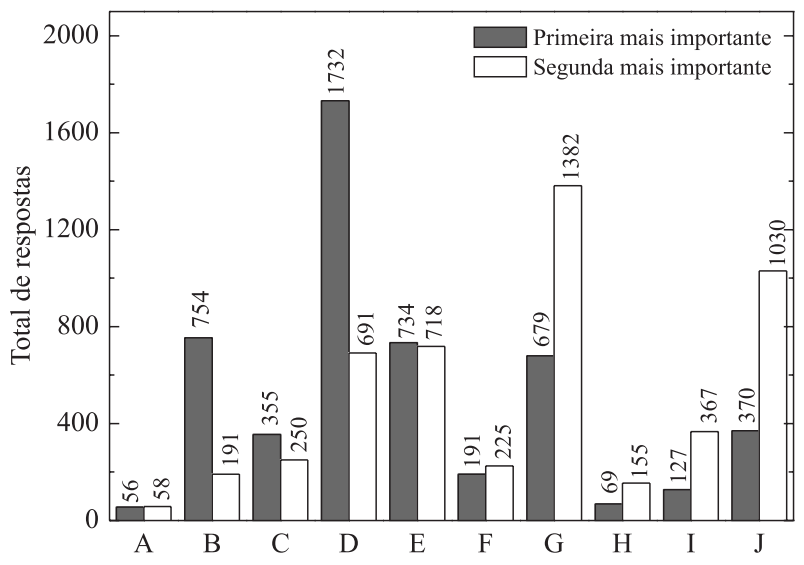

Figura 1. Necessidades formativas consideradas pelos estudantes do Ensino Médio. (A) Sem resposta, (B) Teorias químicas, (C) Ser divertido, (D) Entender as dificuldades dos alunos, (E) Fazer experimentos, $(F)$ Ser exigente, (G) Como dar aulas diferentes, (H) Pesquisar em Química, (I) Ser amigo, (J) Mostrar aplicações da Química

Na segunda ordem de importância, o segundo mais importante (SI), foram obtidas 5.009 respostas. Nessa categoria, a alternativa mais valorizada pelos estudantes foi como dar aulas diferentes, com $1.382(27,27 \%)$ respostas, seguida por mostrar aplicações da Química com $1.030(20,33 \%)$ respostas, enquanto que a alternativa com o menor percentual de respostas foi novamente pesquisar em Química (3,06\%).

$\mathrm{Na}$ perspectiva de elucidar a compreensão que os estudantes manifestaram com base nas suas escolhas em relação às alternativas da questão, foram verificados os relatos dos 81 entrevistados, em reposta à mesma pergunta - Em sua opinião, o que a universidade 
deve ensinar para quem deseja ser professor de Química? As respostas obtidas foram organizadas em três categorias de saberes, conforme mencionado na seção anterior: conhecimento da matéria a ser ensinada; conhecimento pedagógico - saber relacionar-se com os alunos e saber preparar e conduzir as atividades de ensino; compromisso ético e moral. Sendo que a categoria que concentrou o maior número de respostas foi conhecimento pedagógico.

Foi possível, portanto, depreender que entender as dificuldades dos alunos implica que o professor deveria conhecer os alunos, os processos cognitivos e desenvolvimentos de como os alunos aprendem. Isso é necessário para que o professor possa perceber e compreender os problemas, com a finalidade de refletir sobre estes e buscar as soluções para o melhor aprendizado do aluno. ${ }^{15-18} \mathrm{O}$ trecho do relato abaixo ilustra esse tipo de manifestação:

[...] tentar entender o aluno, quando ele não tá entendo algo da tua matéria, tentar entendê-lo e não já ir perdendo a paciência, que a gente não pode aprender também o que a gente não entende. Ser paciente com aquele aluno e tentar entender o problema na sala de aula, não na universidade, e..., é bolar umas aulas mais interessantes, assim não só ficar naquela sala de aula, sala de aula, levar pro laboratório e fazer coisas novas (Escola 1, Aluno 2).

Com relação ao mais importante da ordem SI, a alternativa como dar aulas diferentes (Figura 1) também configura um dos apontamentos - saber dirigir o trabalho dos alunos - que Carvalho e Gil-Pérez ${ }^{18}$ apresentam como sendo necessário para a formação do professor.

Nessa perspectiva, os relatos apontam que o estudante entende que o professor deveria ser preparado pela universidade para realizar atividades mais dinâmicas, como aquelas em que o aluno possa ser mais ativo e participe como sujeito da construção do seu conhecimento, como mostram os depoimentos a seguir:

Deve ensinar a ter mais aulas dinâmicas, não ficar só naquela coisa, livro e caderno, porque isso enjoa o aluno, porque a gente vê isso sempre, a gente só estuda praticamente com isso. Daí sempre ter só isso, aí acaba ficando chato, ainda mais pra quem tá começando a estudar, daí vai ter praticamente muitos anos ainda pra enjoar do caderno e do livro, né? Daí ter umas aulas diferentes no meio assim, pra ficar diferente, seria bem legal! (Escola 13, Aluno 3).

Bom, além da Química em si, dá um ensino pedagógico, assim, como tá em sala de aula, como agir em sala de aula, além de passar a Química, né? Tem que ensinar também como repassar essa Química (Escola 14, Aluno 1).

Além disso, foi possível observar outros aspectos interessantes relacionados à formação inicial do professor de Química: o entendimento que o estudante tem sobre preparar o futuro professor para saber se expressar em público; aproximação entre universidade e escola e, o papel do professor formador na formação do futuro professor, assim como pode ser observado nos trechos a seguir:

[...] como a gente pode ver, assim, alunos novos, pessoas novas que vêm dar aula de Química e que têm aquela certa timidez de falar, de se expor com os alunos. Acho que deveria realmente tratar essa... Trabalhar essa parte pessoal da pessoa (Escola 9, Aluno 1).

[...] como lidar com o ser humano, é essas coisas, porque o professor, às vezes, ele sabe como interpretar a matéria pro aluno, ou como compreender o aluno, ou como conversar, então deveria ser isso [...].

[...] porque eu acho também que a culpa disso não é do aluno lá dentro da universidade, mas de professores lá dentro da universidade que não sabem interagir, porque, queira ou não, o aluno que tá lá dentro, hoje são alunos, amanhã vão ser professores, então eles vão se espelhar em professores de Química lá de dentro da universidade, então será que ele vai dar aula das mesmas coisas de Química, e o professor lá de dentro da universidade, se não for uma pessoa interativa, criativa, uma pessoa que saiba lidar... será que esse aluno, ao sair de lá, ele vai saber lidar com isso? São essas coisas que precisam ser ampliada que faltam, mas devia ser ampliada (Escola 20, Aluno 1).

Por fim, para os estudantes do Ensino Médio, a universidade deveria ensinar ao futuro professor de Química, conhecimentos que permitam que ele possa entender as dificuldades dos alunos e dar aulas diferentes das tradicionais. Desse modo, foi possível verificar que a percepção dos estudantes a respeito do que o professor de Química precisa saber dialoga com as necessidades formativas apontadas na literatura e presente nas atuais determinações legais. ${ }^{11-20}$ Tanto nos relatos como nas questões fechadas, os estudantes manifestaram suas percepções em torno do conhecimento pedagógico. O percentual apresentado por essa categoria demonstra quanto é significativo e necessário para o aluno que o professor saiba mobilizar esses conhecimentos como forma de melhorar sua prática, agregando ainda, o compromisso com a profissão.

\section{CONSIDERAÇÕES FINAIS}

As expectativas dos estudantes do Ensino Médio em relação aos futuros professores de Química são que estes sejam capazes de: desenvolver atividades diferentes, em que os estudantes possam ser mais ativos; apresentar boa explicação dos conteúdos; ter boa interação com aluno; ter domínio do conteúdo; saiba mostrar a relação do conteúdo com o cotidiano; realizar aulas experimentais; relacionar a Química com assuntos atuais e, ser comprometido eticamente com a sua profissão. Nesse sentido, cabe retomar a fala do Aluno 1 (Escola 20), pois ele expressa que, para que o futuro professor de Química saiba interagir com os estudantes e trabalhar de forma interativa e criativa, é necessário que dentro da instituição formadora ele vivencie situações que promovam essas qualidades, ou seja, que o docente formador também tenha essas atitudes para com os licenciandos.

Os resultados da pesquisa realizada com os estudantes do Ensino Médio apontam para a necessidade de aproximação entre universidade e escolas, visto que os estudantes, que estão vivenciando o ensino de Química, apontam para as reais dificuldades presentes no dia a dia nas escolas e, em geral, as IES caminham na direção oposta às necessidades da Educação Básica, para as quais as Instituições de Ensino Superior estão formando esses profissionais.

\section{AGRADECIMENTOS}

Às Gestões escolares, professores e estudantes da $3^{\mathrm{a}}$ série do Ensino Médio das escolas públicas das redes estaduais de ensino da região Norte, pela participação e colaboração nesta pesquisa.

À Fapeam, Sect e Governo do Estado do Amazonas, pelo auxílio financeiro.

\section{REFERÊNCIAS}

1. Kasseboehmer, A. C.; Dissertação de Mestrado, Universidade Federal de São Carlos, Brasil, 2006. 
2. Kassemboehmer, A. C.; Ferreira, L. H.; Quim. Nova 2008, 31, 694.

3. Marques, C. V. V. C. O.; Tese de Doutorado, Universidade Federal de São Carlos, Brasil, 2010.

4. Francisco Júnior, W. E.; Peternele, W. S.; Yamashita, M.; Química Nova na Escola 2009, 31, 113.

5. Mesquita, N. A. S.; Soares, M. H. F. B.; Química Nova na Escola 2009, $31,123$.

6. Santos, W. L. P.; Gauche, R.; Silva, R. R.; Quim. Nova 1997, 20, 675.

7. Gauche, R.; Silva, R. R.; Baptista, J. A.; Santos, W. L. P.; Mól, G. S.; Machado, P. F. L.; Química Nova na Escola 2008, 27, 26.

8. Baptista, J. A.; Silva, R. R.; Gauche, R.; Machado, P. F. L.; Santos, W. L. P.; Mól, G. S.; Química Nova na Escola 2009, 31, 140.

9. Garcia, I. T. S.; Kruger, V.; Quim. Nova 2009, 32, 2218.

10. http://www.sbq.org.br/graduacao.php, acessada em Novembro 2011.

11. http://portal.mec.gov.br/sesu/arquivos/pdf/0802Quimica.pdf, acessada em Novembro 2011.

12. http://portal.mec.gov.br/sesu/arquivos/pdf/130301Quimica.pdf, acessada em Novembro 2011.

13. http://portal.mec.gov.br/sesu/arquivos/pdf/00901formprof.pdf, acessada em Novembro 2011.
14. http://portal.mec.gov.br/seb/arquivos/pdf/CienciasNatureza.pdf, acessada em Novembro 2011.

15. Shulman, L. S.; Educ. Res. 1986, 15, 4.

16. Shulman, L. S.; Harvard Educational Review 1987, 57, 1.

17. Cunha, M. I.; O bom professor e sua prática, $17^{\mathrm{a}}$ ed., Papirus: Campinas, 2005.

18. Carvalho, A. M. P.; Gil-Pérez, D.; Formação de professores de Ciências: tendências e inovações, Cortez: São Paulo, 2006.

19. Freire, P.; Pedagogia da autonomia: saberes necessários à prática educativa, Paz e Terra: São Paulo, 2001.

20. Imbernón, F.; Formação docente e profissional: formar-se para a mudança e a incerteza, Cortez: São Paulo, 2009.

21. Fraser, M. T. D.; Gondim, S. M. G.; Paidéia 2004, 14, 139.

22. Maldaner, O. A.; A Formação Inicial e Continuada de Professores de Química: professores/pesquisadores, Ed. Unijuí: Ijuí, 2006.

23. Bardin, L.; Análise de Conteúdo, Edições 70: Lisboa, 2009.

24. http: //portal.inep.gov.br/basica-censo-escolar-sinopse-sinopse,, acessada em Novembro 2011. 